\title{
A short course of prednisolone in patients with moderate Covid 19 respiratory failure- stop the progression a case series.
}

Dale Ventour ( $\square$ daleventour@hotmail.com )

UWI: University of the West Indies https://orcid.org/0000-0001-9518-9616

Rheana Sieunarine

Eric Williams Medical Sciences Complex

Chavin Gopaul

University of the West Indies (UWI)

\section{Research Article}

Keywords: Progression to Invasive Ventilation, Dexamethasone, Supplementary Oxygen Therapy, Shortness of Breath

Posted Date: June 9th, 2021

DOl: https://doi.org/10.21203/rs.3.rs-542324/v1

License: (c) (i) This work is licensed under a Creative Commons Attribution 4.0 International License. Read Full License

Version of Record: A version of this preprint was published at Journal of Investigative Medicine High Impact Case Reports on January 1st, 2022. See the published version at https://doi.org/10.1177/23247096221090843. 


\section{Abstract}

Introduction This case series outlines the results of using prednisolone in patients with moderated respiratory failure secondary to Covid 19 pneumonitis to prevent the progression to invasive ventilation. There is no consensus on the use of prednisolone in Moderate Covid respiratory failure early in the pandemic this should be an additional option where Dexamethasone is not available. Consent was obtained by the patients for anonymous publication of their data.

Clinical Findings The author provides evidence of four (4) Covid 19 positive cases admitted to the High dependency Unit with moderate respiratory failure, defined as needing supplementary oxygen therapy to maintain saturations above $90 \%$, who when treated with prednisolone rapidly decreased their oxygen requirement and were successfully weaned to room air within 72 hours of initiation of steroids.

Diagnosis Four (4) patients admitted to the High Dependency Unit diagnosed with moderate respiratory failure secondary to PCR positive Covid 19.

Intervention Covid 19 positive patients requiring oxygen therapy to maintain saturations above $90 \%$ were given a trial of oral prednisolone between $15-30 \mathrm{mg}$ until they were weaned to room air maintaining saturations $>95 \%$.

Outcome Rapid resolution of worsening respiratory function of Covid 19 positive patients within the High Dependency unit in a tertiary medical center. The signs and symptoms of respiratory failure resolved after 72 hours of prednisolone treatment and none of these patients were escalated to non-invasive or invasive respiratory support. The patients were kept for a further 48 hours after the steroids were discontinued to monitor for relapse of symptoms which none of them had.

Conclusion Initiation of a prednisolone steroid trial must be considered in Covid 19 positive patients needing supplementary oxygen therapy or developing worsening shortness of breath. Early Covid respiratory failure responds to a low dose for a short duration and prevents escalation to noninvasive/invasive respiratory support.

\section{Take Home Message}

A prednisolone trial instituted early in moderate respiratory failure Covid positive patients prevents progression to worsening respiratory failure.

\section{Introduction}

In this Caribbean Territory we were able to organize a parallel health care system which addressed Covid 19 positive patients. This allowed us to quarantine this cohort of patients from the general population. All Covid positive patients were admitted to a medical facility as such it provided an unusual opportunity to manage these cases in one place. The author presents four (4) patients who escalated respiratory care 
from the ward to the High Dependency unit. Early in the pandemic approximately $50 \%$ of these High Dependency patients progressed to the Intensive care needing ventilation with high mortality, we initiated corticosteroids after recognizing the "cytokine storm" that these patients exhibit. This paper outlines the results of these interventions and our intervention which led to no further invasively ventilated patient or mortality. There is no consensus on the use of corticosteroids in Moderate Covid respiratory failure and while it's use in severe Covid respiratory failure is not recommended unless the patient has sepsis syndrome.

\section{Clinical Findings}

\section{Case 1}

A 62-year-old, diabetic, hypertensive patient was admitted to the ward after testing positive on the $21^{\text {st }}$ March. He was on Nifedipine, Metformin, Azithromycin, hydroxychloroquine, Tamiflu, Ceftriaxone and was dyspneic with $\mathrm{SpO}_{2} 76 \%$ on room air leading to admission to the High Dependency Unit on the $22^{\text {nd }}$ March. He had bilateral pneumonia on chest X-ray, very short of breath when conversing but able to complete sentences. He was restricted to strict bed rest but his oxygen requirements did not wean until the $30^{\text {th }}$ March when he was started on $20 \mathrm{mg}$ prednisolone daily. His oxygen requirement decreased over the next $48 \mathrm{hrs}$. as he was weaned to nasal cannula $2 \mathrm{~L} /$ min achieving $\mathrm{SpO}_{2} 98 \%$ and less breathlessness. He was allowed to ambulate and was weaned to room air after 4 days and the prednisolone was rapidly tapered as his blood sugar control was difficult. Lactate dehydrogenase on admission to HDU was $1536 \mathrm{U} / \mathrm{I}(100-190 \mathrm{U} / \mathrm{I})$.

\section{Case 2}

A 65-year -old, diabetic, hypertensive, obese, Covid positive patient admitted to the ward on $27^{\text {th }}$ March. His therapy at the time was hydroxychloroquine, azithromycin, Tamiflu and Ceftriaxone. He was admitted to the High Dependency unit on the $1^{\text {st }}$ April after needing escalating oxygen therapy and worsening shortness of breath ( $60 \%$ venti-component with $\mathrm{SpO}_{2} 92 \%$ ). He needed a sliding scale of insulin to control his very labile blood sugar and prednisolone $30 \mathrm{mg}$ was initiates after 5 days of shortness of breath and hypoxia. His oxygen requirement markedly reduced over 3 days and he was able to maintain $\mathrm{SpO}_{2} 95 \%$ on $11 /$ min nasal cannula. The prednisolone was rapidly weaned over another 4 days as his blood sugar was even more difficult to control, he was then allowed to full ambulate. Lactate dehydrogenase on admission to HDU $1345 \mathrm{U} / \mathrm{I}(100-190 \mathrm{U} / \mathrm{I})$.

\section{Case 3}

A 41-year-old, asthmatic on inhalers admitted to HDU on $28^{\text {th }}$ March with shortness of breath and supplementary oxygen venti-component $60 \%$ to achieve $\mathrm{SpO}_{2} 95 \%$ ( $85 \%$ on room air). The patient had shortness of breath from the $26^{\text {th }}$ March and worsening wheeze; he was taking Salbutamol, Symbicort, Azithromycin, Tamiflu, Co-amoxiclav and Hydroxychloroquine. On 29/3, his chest was more productive 
(yellow sputum), and his antibiotics were changed to Ceftriaxone and his $\mathrm{SpO}_{2}$ maintained at $88 \%$ on a $60 \%$ venti-component.

He remained oxygen dependent until the $1^{\text {st }}$ April when he was started on oral prednisolone $30 \mathrm{mg}$ daily and continued his salbutamol and ipratropium bromide, his oxygen was weaned to room air on the $3^{\text {rd }}$ April when he maintained oxygen saturation of $98 \%$. He continued to have a mild wheeze which subsided on the $5^{\text {th }}$ April and the prednisolone was weaned over the next 2 days as he remained on room air. $\mathrm{He}$ was discharged on the $6^{\text {th }}$ April to the ward, asymptomatic and well. Lactate dehydrogenase on admission to HDU $1358 \mathrm{U} / \mathrm{I}(100-190 \mathrm{U} / \mathrm{I})$.

\section{Case 4}

A 78-year-old hypertensive patient was admitted to the ward on the $4^{\text {th }}$ April after testing positive for Covid the day before. He developed progressive delirium and hypoxia leading to admission to the High Dependency Unit, his $\mathrm{SpO}_{2}$ on admission was $91 \%$ on a $60 \%$ venti-component. He was very agitated and confused, $15 \mathrm{mg}$ prednisolone was commenced on the $6^{\text {th }}$ April as his oxygen requirements remained high and strict bed rest was ordered. His treatment on admission to the HDU included azithromycin, Tamiflu, Ceftriaxone, Omeprazole. Saturations improved over the next 4 days and he was placed on nasal specs and allowed to ambulate. The prednisolone was weaned over the next 3 days and the patient was discharged to the ward. Lactate dehydrogenase $1246 \mathrm{U} / \mathrm{I}(100-190 \mathrm{U} / \mathrm{I})$.

\section{DIAGNOSIS}

Four (4) patients admitted to the High Dependency Unit diagnosed with moderate respiratory failure secondary to PCR positive Covid 19.

\section{THERAPEUTIC INTERVENTION}

Prednisolone therapy was initiated after patients needed oxygen therapy to maintain saturations $>90 \%$, these patients remained hypoxic for 72 hours within the HDU prior to the initiation of prednisolone therapy. The dose varied as we have a high percentage of Diabetes in our population so glycaemic control was difficult. The dose of prednisolone was between $15-30 \mathrm{mg}$ and this treatment continued until the patients were maintaining saturations $>92 \%$ and relief of dyspnoea.

\section{OUTCOME}

There was resolution of dyspnoea and oxygen dependency within 72 hours of initiation of steroid therapy. The dose varied from 15-30 mg and within 48 hours all patients were weaned to nasal cannula and there was a marked improvement in chest tightness and dyspnea. The course of prednisolone therapy varied from three (3) to seven (7) days with patients not needing maintenance steroid therapy during the recovery phase. All patients were subsequently discharged from the institution after having two (2) negative nasopharyngeal swabs. There was no readmission for respiratory support. 


\section{Conclusion}

Initiation of a 'prednisolone trial', if Dexamethasone is not available, should be considered in Covid 19 positive patients needing supplementary oxygen therapy or developing worsening shortness of breath. Early Covid respiratory failure responds to a low dose for a short duration and prevents escalation to noninvasive/invasive respiratory support.

\section{Abbreviations}

Covid 19- Coronavirus 2019; mg-milligrams; HDU-high dependency unit; $\mathrm{SpO}_{2}$-pulse oximetry saturations; H1N1- haemagglutinin 1 neuramindase1antigen, II- interleukin.

\section{Declarations}

\section{Consent for participation}

The patients involved were contact via the telephone for verbal consent and it was highlighted that no identifiable information was revealed in the paper. They all consented for the use of their information.

\section{Ethical Approval and Consent to Participate}

Ethics approval was obtained by the hospital's ethics committee for this publication

Verbal consent was obtained for the patients involved in the case presentation.

\section{Consent for Publication}

N/A

\section{Availability of Data and Materials}

The data was obtained electronically from a password protected data base.

\section{Competing Interest}

No conflict of interest by Author Dr Ventour, Co-authors Drs Sieurnarine and Gopaul

\section{Funding declaration}

No funding received

\section{Authors' contribution}

Conceptualization of manuscript Drs Ventour and Gopaul. Data collection Dr Sieunarine/Ventour, Draft Dr Ventour. All authors have read and approved the manuscript. 
Acknowledgement

None

\section{References}

1. Clark D Russell, Jonathan E Millar, J Kenneth Baillie. Clinical evidence does not support corticosteroid treatment for 2019-nCoV lung injury. The Lancet, 2020.

2. Epler GR, Colby TV, McLoud TC, Carrington CB, Gaensler EA. Bronchiolitis obliterans organizing pneumonia. N Engl J Med 1985;312:152-158.

3. M Cai, F Bonella, H Dai, R Sarria, J Guzman et al. Macrolides inhibit cytokine production by alveolar macrophages in bronchiolitis obliterans organizing pneumonia. Immunobiology, 2013; Volume 218, Issue 6, June 2013, Pages 930-937

4. Qin C, Zhou L, Hu Z et al (2020) Dysregulation of immune response in patients with COVID-19 in Wuhan, China. Clin Infect Dis. https://doi.org/10.1093/cid/ciaa248 